\title{
Literature Review: Stress Reactance in Psoriatic Patients
}

W. Michael Hooten, MD

John Hopkins School of Medicine, Baltimore, MD

Follow this and additional works at: https://jdc.jefferson.edu/jeffjpsychiatry

Part of the Psychiatry Commons

Let us know how access to this document benefits you

\section{Recommended Citation}

Hooten, MD, W. Michael (1994) "Literature Review: Stress Reactance in Psoriatic Patients," Jefferson Journal of Psychiatry. Vol. 12 : Iss. 1 , Article 9.

DOI: https://doi.org/10.29046/JJP.012.1.006

Available at: https://jdc.jefferson.edu/jeffjpsychiatry/vol12/iss1/9

This Article is brought to you for free and open access by the Jefferson Digital Commons. The Jefferson Digital Commons is a service of Thomas Jefferson University's Center for Teaching and Learning (CTL). The Commons is a showcase for Jefferson books and journals, peer-reviewed scholarly publications, unique historical collections from the University archives, and teaching tools. The Jefferson Digital Commons allows researchers and interested readers anywhere in the world to learn about and keep up to date with Jefferson scholarship. This article has been accepted for inclusion in Jefferson Journal of Psychiatry by an authorized administrator of the Jefferson Digital Commons. For more information, please contact: JeffersonDigitalCommons@jefferson.edu. 


\title{
Literature Review: Stress Reactance in Psoriatic Patients
}

\author{
W. Michael Hooten, M.D.
}

\begin{abstract}
The association between stress and psoriasis is well documented. A subgroup of psoriatic patients appear to be high stress reactors who can identify specific psychosocial stresses which exacerbate their psoriasis. In contrast, low stress reactors report no association between stress and the exacerbation of psoriasis. In differentiating high versus low stress reactors, a review of the literature suggests: 1) a neurogenic mediated disease process; 2) high stress reactors' disease course is not confounded by underlying psychopathology and, 3) high stress psoriatics experience more disease related stress than low stress reactors.
\end{abstract}

\section{BACKGROUND}

The term psoriasis originated from the Greek word psorian, meaning to have the itch and was first described by Celsus (25 B.C. -45 A.D.) in his work De Re Medica $(1,2)$. Many early psoriatics were misdiagnosed as suffering from leprosy, impetigo, scabies or pyoderma $(1,2)$. In 1809 , Robert Willan was the first to partially differentiate psoriasis from other skin diseases and in 1841, Hebra described psoriasis as a separate clinical entity (1).

Psoriasis is a papulosquamous exfoliative dermatitis which presents as discrete flat-topped papules or plaques covered with thin, white, loosely adherent scales. Frequently, psoriasis initially appears on the scalp and then spreads to involve the back, sacrum, palms, nails and the extensor surface of the extremities (3). The prevalence of psoriasis in the general population varies from $0.1-2.48 \%$ with a mean age of onset of 27.8 years (4). Psoriasis is a chronic relapsing disease with $39 \%$ of psoriatics reporting complete symptomatic resolution at least once during the course of the disease $(4,5)$.

\section{PATHOPHYSIOLOGY}

The pathogenesis of psoriasis has yet to be fully elucidated. An increased incidence of disease in association with certain HLA types suggests that genetic factors participate in the predisposition for disease development (6). Abnormalities in keratinocyte proliferation induced by $\mathrm{T}$ lymphocytes, alterations in cell-mediated

W. Michael Hooten, M.D. is a second year psychiatry resident at Johns Hopkins School of Medicine in Baltimore. 
reactivity and a complement-mediated reaction localized to the stratum corneum have all been implicated in the pathogensis of psoriasis (7-9).

In a series of reports, Farber proposed a neuropeptide-induced neurogenic inflammatory mechanism (10-14). This theory suggests that the release of substance $\mathrm{P}$ by local or systemic factors from sensory nerves in the skin causes local inflammatory responses that trigger psoriasis. The skin is innervated by unmyelinated sensory fibers and substance $\mathrm{P}$ has been localized in the free nerve endings located in the dermal papillae and epidermis of healthy human skin $(15,16)$. Substance $\mathrm{P}$ is released by an antidromic mechanism following stimulation of nociceptors resulting in a wheal (plasma protein extravasation) and flare (vasodilation) (17). By way of afferent C fibers to the spinal cord, ascending nerve tract fibers transmit sensory information to the thalamus and higher cortical centers. Decending pathways then relay information back to the spinal cord.

Although local release of neuropeptides from sensory nerves in the skin has not been measured in response to stressful stimuli, the activation of higher cortical areas during stress results in altered release of substance $\mathrm{P}$ from the adrenal gland by descending autonomic fibers (18). Some of these descending autonomic fibers innervate opioid interneurons in the dorsal horn which synapse with substance P-containing nerves in the spinal cord (19). In response to stress, Farber proposed that descending autonomic nerves trigger antidromic release of substance $\mathrm{P}$ in the skin which would partly explain the effects of emotional stress on skin physiology (14). Experimental data sited by Farber in support of this hypothesis includes the decreased response of dorsal-horn neurons to noxious stimuli following activation of higher cortical centers and the exacerbation of adjuvant-induced arthritis $(13,14,20,21)$. In the cases of surgically induced sensory anesthesia, a slow recurrence of psoriasis parallels the return of cutaneous sensation (12). In related animal studies, substance P-containing nerve fibers regenerate during burn wound healing (22). This suggests that the recurrence of psoriasis following surgically induced anesthesia could result from the regeneration of substance-P containing nerve fibers. Further evidence includes the successful use of topical capsaicin in the treatment of moderate to severe psoriasis (23). The beneficial effects of capsaicin are most likely related to the depletion of substance $\mathbf{P}$ from local sensory nerve terminals $(24,25)$.

\section{STRESS}

There is a large body of literature associating stress and the development or exacerbation of psoriatic lesions (26-40). From the literature, it is possible to identify a subgroup of psoriatic patients who appear to be high stress reactors. These patients report that psychosocial stress exacerbates their psoriasis. In contrast, low stress reactors report no association between stress and the exacerbation of psoriasis. In a survey involving 2144 psoriatic patients, $40 \%$ indicated that psoriatic lesions appeared at "times of worry" (5). In another survey involving 5600 psoriatic patients, $33 \%$ responded that "new patches" of psoriasis appeared during periods of "worry" (4). In an attempt to further characterize patients who report an increase in psoratic 
symptoms in response to stress, Gupta established a broad psychocutaneous profile of patients who were self reported high stress reactors versus those who were low stress reactors (27). The patients were asked to self-rate the extent to which stressful situations made their psoriasis worse. They were asked to respond to the following statement: "Stressful situations frequently make my psoriasis worse." The patients were asked to record their responses on a 10-point scale with 1 denoting "not at all" and 10 "very markedly." The median score was 7. Patients with scores of 7 or higher were categorized as "high stress reactors" and those with ratings of 1 to 6 as "low stress reactors." In a study of 127 consecutive psoriatic patients, high stress reactors exhibited more cosmetically disfiguring disease in conspicuous areas (i.e., scalp, face, neck, forearms, hands, genital region) (27). However, the overall severity of psoriatic lesions as measured by the percentage of total body surface area affected and the degree of plaque thickness, scaling and erythema did not differ significantly from low stress reactors. By way of the Hassles Scale, a self-rated 10-point scale measuring the degree of daily stress resulting directly from psoriasis, and the Psoriasis Life Stress Inventory (PLSI), a 41 item instrument designed to measure stress resulting from the impact of psoriasis upon the quality of life, Gupta showed that high stress reactors reported more disease-related stress (27). Among high stress reactors, diseaserelated stress scores (Hassles score) correlated directly with psoriasis severity in cosmetically conspicuous body regions (scalp, face, neck, forearms, hands and genital region). Similarly, in a 5 year retrospective study, Baughman and Sobel found a greater stress reactance among patients with moderately severe psoriasis (35). When similar analysis was performed to determine if the amount of stress experienced over the 5 year study period influenced the degree of stress reactance, no such influence was found. Although Baughman and Sobel did not comment on the causal relationship between the degree of stress reactance and psoriasis severity, Gupta postulated that the amount of disease-related stress experienced by high stress reactors was a result of cosmetic disfigurement, which adversely impacted appearance and sexuality.

When compared with scores from the Social Readjustment Rating Scale (SRRS), which measured stress resulting from major life events during the 6 months prior to the study, high stress reactors experienced more disease-related stress in contrast to stress resulting from major life events (27). Baughman and Sobel postulated that psoriasis accounts for the variation in stress and that a person suffering with psoriasis is more prone to interpret life as stressful when compared to an individual who does not have the disease (35).

The prognostic significance of a high versus low stress reactor in terms of relapse has not been firmly established. In a series of 183 consecutive psoriatic patients followed over a three year period, those who recalled the occurrance of a specific stress within one month prior to the first psoriatic attack were less likely to relapse (37). The incubation time for specific incidents of stress and the development of psoriatic plaques was 2 days to 4 weeks in $96 \%$ of patients. These results were interpreted by Seville in terms of insight, where insight was defined as "selfknowledge resulting in an understanding in depth with full acceptance" $(38,39)$. 
Those patients who were able to recall a specific stressor were deemed more insightful and thus less likely to relapse as opposed to those who could not recall a stressor. Gupta found that high stress reactors experienced a greater number of flare-ups 6 months prior to admission ( $p<0.05)$ (27). Sevill's observations suggest that the acknowledgement of previous stressors could help reduce relapse but Gupta's more recent empirical findings reveal that high stress reactors are prone to relapse.

\section{PSYCHOPATHOLOGY}

There have been many unsuccessful attempts to identify specific personality traits which characterize psoriatics $(32,33,35,40-46)$. Two studies were identified which compared personality profiles of high and low stress reactors $(27,35)$. Gupta administered the Interpersonal Dependency Inventory Subscale to a series of high and low stress reactors (27). Stress reactance was determined by way of a 10-point self rated scale as described above. High stress reactors were more interpersonally dependent and tended to rely more upon the approval of others. Additionally, high stress reactors were less likely to report anger in association with their disease and feared greater social disapproval. In contrast, low stress reactors asserted angry feelings in reaction to their disease. In a 5 year retrospective study of 252 psoriatics, low, medium and high stress reactors were identified by the severity of stress (Social Readjustment Scale) and psoriasis (Psoriasis Severity Scale) (35). Following delineation of stress reactance, attempts to identify associated personality traits proved unsuccessful. Considering psoriatics in general, there have been reports of increased psychasthenia, hysteria, depression, anxiety, obsessionality and a distrust of social situations $(33,41-44)$. It is important to note that the presence of the above disorders were established by way of questionnaires and were not the result of a psychiatric evaluation.

There is conflicting evidence concerning the use of alcohol among psoriatic patients. A group of 99 patients consecutively admitted for inpatient treatment of psoriasis and a matched control group hospitalized for other dermatologic disorders were evaluated for alcoholism using the criteria established by the National Council of Alcoholism and by scores on the Self-Administered Alcoholism Screening Test (47). Alcoholism was diagnosed in 11 psoriatic patients and 3 control patients $(0.05<\mathrm{p}<0.10)$. Ten of 11 psoriatic patients compared with 1 of 3 control patients were male $(p<0.05)$. In a 5 year retrospective study of self-reported alcohol consumption greater than 50 gm per day, $5.3 \%$ of 639 individuals who reported drinking greater than $50 \mathrm{gm}$ per day had psoriasis compared to $0.7 \%$ of 1348 who drank less than $50 \mathrm{gm}(\mathrm{p}<0.001)$ (48). Two previous studies utilizing criteria established by the National Council on Alcoholism's Expert Committee and an unspecified questionnaire found no association between psoriasis and alcoholism $(49,50)$. The prevalence of alcoholism among psoriatics is inconclusive, but the data suggest psoriatics could be at higher risk for developing alcoholism. 


\section{CONCLUSION}

When compared to low stress reactors, high stress reactors have more evidence of cosmetically disfiguring disease, experience more disease related stress and are more prone to relapse. However, no personality traits or associated psychiatric disorders have been identified which differentiate stress reactance. Further elucidation of the pathogenesis of psoriasis could potentially allow stress reactance to be differentiated biologically. More study is needed to determine if the course of psoriasis could be altered in high stress reactors by modifying the above distinguishing characteristics.

\section{REFERENCES}

1. Shafii M, Shafii SL: Exploratory psychotherapy in the treatment of psoriasis. Arch Gen Psychiatry 1979; 36:1242-1245

2. Dungey RK, Buselmeier TJ: Medical and psychosocial aspects of psoriasis. Health Soc Work 1982; 7(2):140-147

3. Fiumara NJ: Psoriasis of the penis: Koebner reaction following oral genital exposure. J Am Vener 1976; 3:59-60

4. Farber EM, Nall ML: The natural history of psoriasis in 5600 patients. Dermatologica $1973 ; 148: 1-18$

5. Farber EM, Bright RD, Nall ML: Psoriasis a questionnaire survey of 2144 patients. Arch Dermatol 1968; 98:248-259

6. Nini G, Bianchi L, Iraci S, Camplone G, Spagnuolo A, Adorno D, Papola F: HLA antigens and infantile psoriasis. Acta Derm Venereol Suppl 1989; 146:59-62

7. Valdimarsson H, Baker BS, Jonsdottir I, Fry L: Psoriasis; a disease of abnormal keratinocyte proliferation induced by T lymphocytes. Immunol Today 1986; 7:256-259

8. Krueger GG, Hill HR, Jederberg WW: Inflammatory and immune cell function in psoriasis-a subtle disorder. J Invest Dermatol 1978; 71:189-194

9. Beutner EH: Autoimmunity in psoriasis. Beutner EH, et al (eds.): Immunopathology of the Skin. New York, John Wiley and Sons, 1987, p. 703

10. Farber EM, FrakiJE: Activation pathways in psoriasis. Cutis 1984; 534:535

11. Farber EM, Nickoloff BJ, Recht B, Fraki JE: Stress, symmetry, and psoriasis: possible role of neuropeptides. J Am Acad Dermatol 1986; 14:305-311

12. Farber EM, Lanigan SW, Boer J: The role of cutaneous sensory nerves in the maintenance of psoriasis. Int J Dermatol 1990; 29:418-420

13. Farber EM, Lanigan SW, Rein G: The role of psychoneuroimmunology in the pathogenesis of psoriasis. Cutis 1990; 46:314-316

14. Farber EM, Rein G, Lanigan SE: Stress and psoriasis: psychoneuroimmunologic mechanisms. Int J Dermatol 1991; 30:8-12

15. Wallengren J, Ekman R, Sundler F: Occurrence and distribution of neuropeptides in the human skin. Acta Derm Venereol 1987; 67:185-192

16. Dalsgaard CJ, Jonsson CE, Hokfelt T, Cuello AC: Localization of substance Pimmunoreactive nerve fibers in the human digital skin. Experientia 1983; 39:1018-1020

17. Hagermark O, Hokfelt T, Pernow B: Flare and itch induced by substance P in human skin. J Invest Derm 1978; 71:233-235 
18. Oehme P: Substance P: new aspect to its modulatory function. Acta Bio Med 1980; 39:469-477

19. Levine JD: A spinal opioid synapse mediates the interaction of spinal and brain stem sites in morphine analgesia. Brain Res 1982; 236:85-91

20. Gerhart KD, Yezierski RP, Wilcox TK: Inhibition of primate spinothalamic tract neurons by stimulation in periaqueductal gray. J Neurophysiol 1984; 51:450-466

21. Levine JD: Adjuvant-induced arthritis in rats. J Immunol 1985; 135:843-849

22. Kishimoto S: The regeneration of substance P-containing nerve fibers in the process of burn wound healing in the guinea pig skin. J Invest Dermatol 1984; 83:219-223

23. Bernstein JE, Parish LC, Rapaport M, Rosenbaum MM, Roenigk HH: Effects of topically applied capsaicin on moderate and severe psoriasis bulgaris. J Am Acad Dermatol 1986; 15:504-507

24. Bernstein JE, Swift RM, Soltani K, Lorincz AL: Inhibition of axon reflex vasodilatation by topically applied capsaicin. J Invest Dermatol 1981; 76:394-395

25. Jessell TM, Iversen LL, Cuello AC: Capsaicin-induced depletion of substance P from primary sensory neurons. Brain Res 1978; 152:183-188

26. Gupta MA, Gupta AK, Haberman HF: Psoriasis and psychiatry: an update. Gen Hosp Psychiatry 1987; 9:157-166

27. Gupta MA, Gupta AK, Kirkby SK, Schork NJ, Gorr SK, Ellis CN, Voorhees JJ: A psychocutaneous profile of psoriasis patients who are stress reactors. Gen Hosp Psychiatry $1989 ; 11: 166-173$

28. Arnetz BB, Fjellner B, Eneroth P, Kallner A: Stress and psoriasis: psychoendocrine and metabolic reactions in psoriatic patients during standardized stressor exposure. Psychosom Med 1985; 47:528-541

29. Arnetz BB, Fjellner B, Eneroth P, Kallner A: Endocrine and dermatological concomitants of mental stress. Acta Derm Venereol 1991; (supp.) 156:9-12

30. Gaston L, Lassonde M, Bernier-Buzzanga J, Hodgins S, Chrombez J: Psoriasis and stress: a prospective study. J Am Acad Dermatol 1987; 17:82-86

31. Gaston L, Crombez J, Lassonde M, Bernier-Buzzanga J, Hodgins S: Psychological stress and psoriasis: experimental and prospective correlational studies. Acta Derm Venereol Supp 1991; 156:37-43

32. Susskind W, McGuire RJ: The emotional factor in psoriasis. Scott Med J 1959; 4:503-507

33. Fava GA, Perini GI, Santonastaso P, Fornasa CV: Life events and psychological distress in dermatologic disorders: psoriasis, chronic urticaria and fungal infections. $\mathrm{Br} J$ Med Psychol 1980; 53:277-282

34. Baughman RD, Sobel R: Psoriasis. Arch Dermatol 1970; 101:390-395

35. Baughman R, Sobel R: Psoriasis, stress, and strain. Arch Dermatol 1971; 103:599-605

36. Kantor SD: Stress and psoriasis. Cutis 1990; 46:321-322

37. Seville RH: Psoriasis and stress. BrJ Psychiatry 1977; 97:297-302

38. Seville RH: Psoriasis and stress II. Br J Dermatol 1978; 98:151-153

39. Seville RH: Stress and psoriasis: the importance of insight and empathy in prognosis. J Am Acad Dermatol 1989; 20:97-100

40. van der Schaar WW: Psychometric investigation in 48 Dutch patients suffering from psoriasis. Psychother Psychosom 1976; 27:159-162

41. Hughes JE, Barraclough BM, Hamblin LG, White JE: Psychiatric symptoms in dermatology patients. Br J Psychiatry 1983; 143:51-54

42. Hardy GE, Cotterill JA: A study of depression and obsessionality in dysmorphophobic and psoriatic patients. Br J Psychiatry 1982; 140:19-22 
43. Matussek P, Agerer D, Seibt G: Aggression in depressives and psoriatics. Psychother Psychosom 1985; 43:120-125

44. Gilbert AR, Rodgers DA, Roenigk HH: Personality evaluation in psoriasis. Cleve Clin Q $1973 ; 40: 147-152$

45. Lyketsos GC, Stratigos J, Tawil G, Psaras M, Lyketsos CG: Hostile personality characteristics, dysthymic states and neurotic symptoms in urticaria, psoriasis and alopecia. Psychother Psychosom 1985; 44:122-131

46. Wittkower E: Psychological aspects of psoriasis. Lancet 1946; 1:566-569

47. Morse RM, Perry HO, Hurt RD: Alcoholism and psoriasis. Alcohol Clin Exp Res 1985; 9:396-399

48. Chaput JC, Poynard T, Naveau S, Penso D, Durrmeyer O, Suplisson D: Psoriasis, alcohol and liver disease. Br Med J 1985; 291:25

49. Delaney TJ, Leppard B: Alcohol intake and psoriasis. Acta Derm Venereol 1974; 54:237238

50. Parish LC, Fine E: Alcoholism and skin disease. Int J Dermatol 1985; 24:300-30. 156:139_ 142 